SCIREA Journal of Clinical Medicine

ISSN: 2706-8870

http://www.scirea.org/journal/CM

March 1, 2021

SCIREA

Volume 6, Issue 2, April 2021

\title{
EVALUATION OF NEURO-COGNITIVE FUNCTIONS IN PATIENT WITH OBSTRUCTIVE SLEEP APNEA SYNDROME
}

\author{
Aydın Kant' ${ }^{1}$ Hacer Kuzu Okur², Zerrin Pelin ${ }^{3}$, Hatice Türker ${ }^{4}$ \\ ${ }^{1}$ Department of Chest Diseases, Trabzon Vakfikebir State Hospital, Trabzon, Turkey \\ ${ }^{2}$ Acibadem Altunizade Hospital, Chest Disease Unit, Istanbul, Turkey \\ ${ }^{3}$ Department of Health Sciences, Hasan Kalyoncu University, Gaziantep, Turkey \\ ${ }^{4}$ Süreyyapaşa Chest Diseases and Chest Surgery Training and Research Hospital.
}

\begin{abstract}
Objective: Obstructive sleep apnea syndrome (OSAS) is a disease that causes recurrent episodes of apnea, disrupting sleep integrity, significantly impairing functionality and causing neuropsychiatric disorders. In our study, it was aimed to determine whether there is a relationship between theseverity of OSAS and anxiety and depression and the cognitive dysfunction that may occur due to OSAS and the neuropsychiatric exposure levels of the patients.
\end{abstract}

Methods: The study was performed prospectively. Apnea hypopnea index (AHI) results were determined by polysomnography (PSG). Hospital Anxiety and Depression Scale (HAD) and Trail Making Test were applied to patients with OSAS to determine the ir neuropsychiatric conditions. Findings were evaluated using descriptive statistical methods.

Results: 45 patients were included in the study. There was no statistically significant relationship between AHI score and anxiety and depression in the patients included in thestudy ( $>0.05)$. There was no statistically significant difference between AHI scores and 
Trace A and Trace B durations, Trace A andTrace B errorrates ( $>>0.05)$. While there was no statistically significant difference between the presence of anxiety and the durations of Trace $A$ and Trace B and the rates of Trace A error ( $>>0.05)$, the rates of Trace B error were statistically significantly different $(\mathrm{p}=0.035)$. There was no statistically significant difference between the presence of depression and the duration of Trace A and B, and the rates of Trace $A$ and $B$ error $(p>0.05)$.

Conclusions: The rates of making trace B errors in anxiety cases are higher in patients with OSAS compared to cases without anxiety. However, with the present findings, more studies are needed to determine whether cognitive dysfunction in patients with OSAS causes a change in the perception of anxiety and depression symptoms in this patient population.

Keywords: OSAS, Neuropsychiatric disorders, Anxiety, Depression

\section{Introduction:}

Obstructive sleep apnea syndrome (OSAS) causes recurrent snoring and apnea. Because of these apnea attacks during sleep, patients wake up from sleep. This cycle may disrupt the sleep quality and cause problems for the person to perform the daily activities of the next day. ${ }^{[1]}$ The main diagnostic method in the diagnosis of the disease is still polysomnography. There are many studies in the literature that reveal the relationship between obstructive sleep apnea syndrome and cognitive dysfunction. ${ }^{[2]}$ Sleep breathing problems are common in patients with psychiatric disorders such as depression and anxiety, while vice versa. Hamilton Depression Scale, Beck Depression Inventory, Zung Depression Scale, Geriatric Depression Scale, Hospital Anxiety and depression (HAD) scale are used to diagnose psychiatric disorders. ${ }^{[3]}$ The aim of this study was to determine whether there is a relationship between the severity of OSAS and the frequency of anxiety and depression, which factors are affected by the anxiety and depression in OSAS, the cognitive dysfunction that may occur due to OSAS and whether this disorder causes a change in the perception of anxiety and depression symptoms. 


\section{METHODS}

The study was conducted prospectively between June 2007 and November 2009 among the patients who applied to the Sleep Disorders Unit of Süreyyapaşa Chest Diseases and Chest Surgery Training and Research Hospital.

Inclusion criteria :

$1-\mathrm{AHI} \geq 5$,

2- Consent to participate in the study,

3- Patients are between 20 and 65 years old,

4- Being literate

Exclusion criteria :

1- Patients had received psychiatric treatment for anxiety or depression in the last 6 months,

2- $\quad$ Major neurological, cardiovascular and renal disease,

3- $\quad$ Major respiratory disease other than OSAS (COPD, asthma etc.)

The Epworth Sleepiness Scale and a standard patient questionnaire for the diagnosis of sleep disorders was administered face-to-face, in question-answer form, by a physician trained in sleep disorders. PSG was performed in the sleep laboratory. Apnea Hypopnea Index (AHI) was measured. Patients with an AHI score of 5-29 were grouped as non-severe OSAS (Group A), and patients with an AHI score of 30 and above as severe OSAS (Group B). The HAD Scale and the TrailMaking Test, which is a part of the neuropsychological battery, were applied to the patients to determine their anxiety-depression and cognitive levels. ${ }^{[4]}$ Cut-off points of the HAD Scale were taken as 10 for the anxiety subscale and 7 for the depression subscale. Part A of the trail making test is evaluated as an indicator of attention, while part B is considered an indicator of executive functions. Test completion time and error numbers of the patients were evaluated. Normal values are taken as 36 seconds for part $\mathrm{A}$ and $\leq 81$ seconds for part B. ${ }^{[5]}$ 


\section{Statistical analysis}

Descriptive statistical analysis was performed for all variables investigated in the study. Compliance with the normal distribution of the data obtained by measurement was established using the Kolmogorov Smirnov test. Student's t test was used for data conforming to normal distribution, and Mann-Whitney $U$ test was used for data that did not comply with normal distribution. Categorical variables were analysed using the chi-square test or Fisher's Exact Chi-square. The data obtained by measurement were expressed as mean \pm standard deviation. The data obtained by counting were expressed as number (\%). Correlation analysis was performed using the Spearman's correlation test.

\section{RESULTS}

45 patients were included in the study. The mean age of the cases was $46.75 \pm 9.64,37$ $(82.2 \%)$ were male and $8(17.8 \%)$ were female. While the number of patients in Group A (AHI <30) was 24, the number of patients in Group B (AHI 30) was 21. There was no statistically significant difference between AHI levels and gender, mean age, body mass index, neck diameter and smoking $(\mathrm{p}>0.05)$ (Table 1).

Table 1: Demographic features of the cases

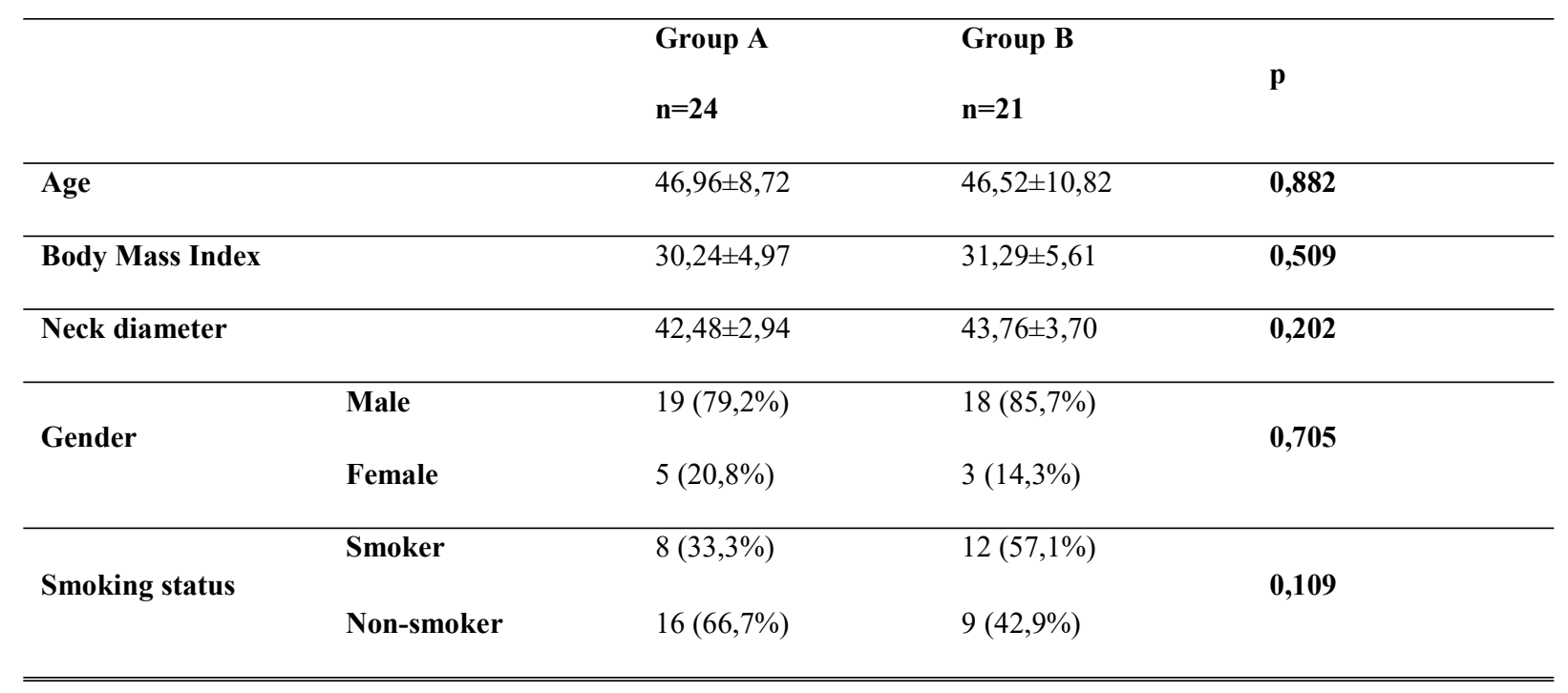

Epworth levels of the patients with AHI score of 30 and above is significantly higher than Epworth levels of cases with AHI level below $30(p=0.013)$. 
No statistically significant correlation was found between AHI score and anxiety, and between AHI score and depression ( $p>0.05)$ (Table 2).

Table 2: Evaluation of HAD Scale According to AHI Status

\begin{tabular}{lllll}
\hline & & Grup A & Grup B & p \\
& & $\mathbf{n = 2 4}$ & $\mathbf{n}=\mathbf{2 1}$ & \\
\hline Anxiety & positive & $6(25,0 \%)$ & $5(23,8 \%)$ & $\mathbf{0 , 9 2 6}$ \\
(cut of 10) & negative & $18(75,0 \%)$ & $16(76,2 \%)$ & \\
\hline Depression & positive & $7(29,2 \%)$ & $9(42,9 \%)$ & $\mathbf{0 , 3 3 8}$ \\
(cut of 7) & negative & $17(70,8 \%)$ & $12(57,1 \%)$ & \\
\hline \hline
\end{tabular}

According to the AHI score, no statistically significant difference was found between the Trace A durations, Trace B durations, Trace A error rates and Trace B error rates $(p>0.05)$ (Table 3).

Table 3: Evaluation of Trail Making Test According to AHI Status

\begin{tabular}{llll}
\hline \hline & Group A & Group B & $\mathbf{p}$ \\
& $\mathbf{n = 2 4}$ & $\mathbf{n = 2 1}$ & \\
\hline Trace A time (sec) & $72,67 \pm 18,37$ & $67,43 \pm 20,57$ & $\mathbf{0 , 3 7 2}$ \\
\hline Trace B time (sec) & $125,08 \pm 32,12$ & $117,90 \pm 36,43$ & $\mathbf{0 , 4 8 6}$ \\
\hline Trace A error n (\%) & 0 & $2(9,5 \%)$ & $\mathbf{0 , 2 1 2}$ \\
\hline Trace B error n (\%) & $16(66,7 \%)$ & $13(61,9 \%)$ & $\mathbf{0 , 7 3 9}$ \\
\hline \hline
\end{tabular}

According to the presence of anxiety, there was no statistically significant difference between the Trace A durations, Trace B durations and Trace A error rates ( $>>0.05)$, while the Trace B error rates were statistically significant $(p=0.035)($ Table 4$)$

Table 4: Evaluations on Anxiety

\begin{tabular}{llll}
\hline \hline & Anxiety (+) & Anxiety (-) & $\mathbf{p}$ \\
& $\mathbf{n}=\mathbf{1 1}$ & $\mathbf{n}=\mathbf{3 4}$ & \\
\hline Trace A time (sec) & $65,00 \pm 12,29$ & $71,91 \pm 21,05$ & $\mathbf{0 , 3 0 9}$ \\
\hline Trace B time (sec) & $121,00 \pm 30,50$ & $121,97 \pm 35,48$ & $\mathbf{0 , 9 3 6}$ \\
\hline Trace A error $\mathbf{n}(\%)$ & 0 & $2(5,9 \%)$ & $\mathbf{1 , 0 0 0}$ \\
\hline
\end{tabular}


There is no significant difference between the duration of Trail A according to the presence of depression $(\mathrm{p}=0.058)$. There is no statistically significant difference between the Trace $\mathrm{B}$ durations, Trace A error rates and Trace B error rates of the patients according to the presence of depression $(\mathrm{p}>0.05)$ (Table 5).

Table 5: Evaluations on Depression

\begin{tabular}{llll}
\hline \hline & $\begin{array}{l}\text { Depression (+) } \\
(\mathbf{n}=\mathbf{1 6})\end{array}$ & Depression (-) \\
& & $\mathbf{( n = 2 9 )}$ & \\
\hline Trace A duration (sec) & $62,87 \pm 11,33$ & $74,27 \pm 21,77$ & $\mathbf{0 , 0 5 8}$ \\
\hline Trace B duration (sn) & $117,56 \pm 24,80$ & $124,03 \pm 38,36$ & $\mathbf{0 , 5 4 7}$ \\
\hline Trace A error n (\%) & 0 & $2(6,9 \%)$ & $\mathbf{0 , 5 3 1}$ \\
\hline Trace B error n(\%) & $12(75,0 \%)$ & $17(58,6 \%)$ & $\mathbf{0 , 2 7 2}$ \\
\hline \hline
\end{tabular}

\section{DISCUSSION}

Sleep disorders are an important symptom of depression, but a chronic sleep disorder can also cause depression. It is known that the need for sleep in human life increases and decreases periodically. Individuals need more or less sleep from time to time. There are many factors affecting the need for sleep, such as job changes and stress disorders. mental activities, depression and stress affect sleep needs. ${ }^{[6]}$ Whether OSAS causes mental disorders and neuropsychiatric diseases has not been fully revealed yet. ${ }^{[7]}$ However, sleep problems were detected in patients with clinical anxiety and depression in examinations. ${ }^{[8]}$

The rate of depression in OSAS varies considerably in studies. Studies have reported very different rates of depression in these patients, ranging from $8 \%$ to $60 \%{ }^{[9-11]}$ In our study, the prevalence of depression in patients with OSAS was found to be $35 \%$. This rate is similar to that of Aloia et al. ${ }^{[12]}$ The rate of anxiety in our patients was found to be $24.4 \%$. As in our study, this rate was found to be $16 \%$ in one of the studies evaluating anxiety in patients with OSAS using the HAD scale, while it was $50 \%$ in another. ${ }^{[11,13]}$

In the study of Kjelsberg et al., a correlation was found between excessive daytime sleepiness and depression, and it was reported that patients with high anxiety and depression scores responded less to CPAP treatment. ${ }^{[14]}$ Although a positive correlation between anxiety and 
OSAS has been reported in the literature, it has been reported that anxiety may be due to sleep deprivation in these patients. ${ }^{[7]}$ In our study, no statistically significant relationship was found between AHI and anxiety. This finding is consistent with the study of Pillar et al. ${ }^{[7]}$ Yue et al. Associated the significantly higher anxiety and depression scores in OSAS with sleep interruption. ${ }^{[15]}$ In our study, no statistically significant difference was found between the two groups with AHI $<30$ and AHI 30 in terms of the frequency of depression. This finding was consistent with the literature. ${ }^{[7]}$ In the study of Sforza et al., significant relationship was not found between AHI score and depression. ${ }^{[11]}$

While there was no statistically significant relationship between Epworth score and depression score in our study, a significant relationship was found between Epworth score and depression in the study by Aloia et al. ${ }^{[12]}$ Again, while there is a significant relationship between depression score and body mass index in the aforementioned study, in our study, there is a positive but not statistically significant relationship between body mass index and HAD scale depression score.

Most of the studies found that global cognitive functionality (four of seven studies) and language functions (three studies) were preserved. In contrast, attention, alertness, executive functions, and memory were impaired in at least $60 \%$ of the studies reviewed. Psychomotor dysfunctions were noted in $80 \%$ of the studies. When both psychomotor speed and fine motor coordination tests were grouped and evaluated under the psychomotor function structure, it was reported that simple psychomotor speed was robust in OSAS, and there was no difference between the OSAS and control groups evaluating finger tapping in any of the two studies. Some other studies have reported a negative correlation between OSAS stage and cognitive functions. There is a positive relationship between the severity of OSAS and the degree of cognitive dysfunction. ${ }^{[16]}$

There are not many studies on OSAS and executive functions and memory assessment. Performance in high-level executive tasks in patients with arousal and attention difficulties requires careful analysis and interpretation. And while making these evaluations, attention capacity should definitely be taken into consideration. ${ }^{[17]}$ In our study, we used TrailMaking Test B to evaluate cognitive functions and TrailMaking Test A to measure attention capacity. Cognitive dysfunction is associated with the severity of the disease. ${ }^{[18]}$ It has been reported that low AHI score may show cause and effect relationship with cognitive dysfunction. ${ }^{[19]}$ 
In the study of Bedard et al., it was shown that the deterioration in general cognitive functions was higher in patients with apnea compared to the general population, and these losses could be improved with the treatments applied. ${ }^{[20]}$

In the study of Knight et al., no significant relationship was found between the frequency of apnea episodes and cognitive functions. ${ }^{[21]}$ Consistently, in our study, there was no statistically significant difference between AHI levels and Trace A durations, Trace A error rates, Trace $\mathrm{B}$ durations and Trace $\mathrm{B}$ error rates.

In conclusion; in our study, when we investigated whether cognitive dysfunction causes a difference in the perception of anxiety and depression symptoms, the rates of trace B error in patients with anxiety are significantly high. However, it is difficult to argue whether cognitive dysfunction in patients with OSAS causes a change in the perception of anxiety and depression symptoms in this patient population. Since there is no study on this subject in the literature, further studies are needed to reveal whether the psychological symptom levels in patients with OSAS are affected by cognitive status.

\section{References}

[1] Guilleminault C, Stoohs R, Clerk A, et al. From obstructive sleep apnea syndrome to upper airway resistance syndrome, consistency of day time sleepiness. Sleep, 1992; 15: 13-16.

[2] El-AdB, LavieP. Effect of sleepapnea on cognitionandmood. International Review of Psychiatry, 2005; 17(4): 277-282.

[3] Sertöz ÖÖ, Mete HE. Bedensel hastalıklarda depresyon. Klinik Psikiyatri, 2004; Ek 2: 63-69.

[4] Zigmond AS, Snaith RP. The hospital anxiety and depression scale. Acta Psychiatr Scand, 1983; 67(6):361-370.

[5] Marsel Mesulam. Davranışsal ve Kognitif Nörolojinin İlkeleri. İkinci baskı. Çeviri Editörü: İ. Hakan Gürvit. Yelkovan yayıncılık. 2004.

[6] Kayalı M. Uyku Bozuklukları. In: Yüksel N (ed). Ruhsal Hastalıklar. Ankara: Çizgi Tıp Yayınevi, 361-86. 2001. 
[7] Pillar G, Lavie P. Psychiatric symptoms in sleep apnea syndrome: effects of gender and respiratory disturbance index. Chest, 1998; 114: 697-703.

[8] Andrews JG, Oei TP. The roles of depression and anxiety in the understanding and treatment of obstructive sleep apnea syndrome. Clin Psychol Rev, 2004; 24: 1031-1049.

[9] Reynolds CF, Kupfer DJ, McEachran AB, et al. Depressive psychpathology in male sleep apneics. J Clin Psychiatry, 1989; 45:287-290.

[10] Kales A, Cadwell AB, Cadieux RJ, et al. Severe obstructive sleep apnea-II: associated psychopathology and psychosocial consequences. J Chron Dis, 1985; 38:427-434.

[11] Sforza E, De Saint Hilaire Z, Pelissolo A, et al. Personality, anxiety and mood traits in patients with sleep-related breathing disorders: effect of reduced day time alertness. Sleep Med, 2002; 3:139-145.

[12] Aloia MS, Arnedt JT, Smith L, et al. Examining the construct of depression in obstructive sleep apnea syndrome. Sleep Med, 2005; 6 (2):115-121.

[13] Doherty LS, Kiely JL, Lawless G, et al. Impact of nasal continuous positive airway pressure therapy on the quality of life of bedpartners of patients with obstructive sleep apnea syndrome. Chest, 2003; 124:2209-2214.

[14] Kjelsberg FN, Ruud EA, Stavem K. Predictors of Symptoms of Anxiety and Depression in obstructive sleep apnea. Sleep Medicine, 2005; 6:341-346.

[15] Yue W, Hao W, Liu P, et al. A case-control study on psycological symptoms in sleep apnea-hypopnea syndrome. Can J Psychiatry, 2003; 48:318-323.

[16] Aloia MS, Arnedt JT, Davis JD, et al. Neuropsychological sequelae of obstructive sleep apnea-hypopnea syndrome: a critical review. J Int Neuropsychol Soc. 2004;10(5):772785 .

[17] Verstraeten E, Cluydts R, Pevernagie D, et al. Executive function in sleep apnea: controlling for attentional capacity in assessing executive attention. Sleep, 2004; 27:685693.

[18] Saunamaki T, Jehkonen M. A review of executive functions in obstructive sleep apnea syndrome. Acta Neurol Scand, 2007; 115: 1-11. 
[19] Cohen-Zion M, Stepnowsky C, Marler, et al. Changes in cognitive function associated with sleep disordered breathing in older people. J Am Geriatr Soc, 2001; 49(12):16221627.

[20] Bedard MA, Montplaisir J, Malo J, et al. Persistent neuropsychological deficits and vigilance impairment in sleep apnea syndrome after treatment with continuous positive airway pressure (CPAP). J Clin Exp Neuropsychol, 1993;15:330-341.

[21] Knight H, Millman RP, Gur RC, et al. Clinical significance of sleep apnea in the elderly. Am Rev Respir Dis, 1987; 136:845-850. 